\title{
Trinuclear Silver(I) Complexes of Fluorinated Pyrazolates
}

H. V. Rasika Dias, ${ }^{*}$ Chammi S. Palehepitiya Gamage, Jeremy Keltner, Himashinie V. K.

Diyabalanage, Ivan Omari, Yvonne Eyobo, Nadeeka R. Dias, Nathan Roehr, Lesly McKinney, Theresa Poth

Supplementary materials 

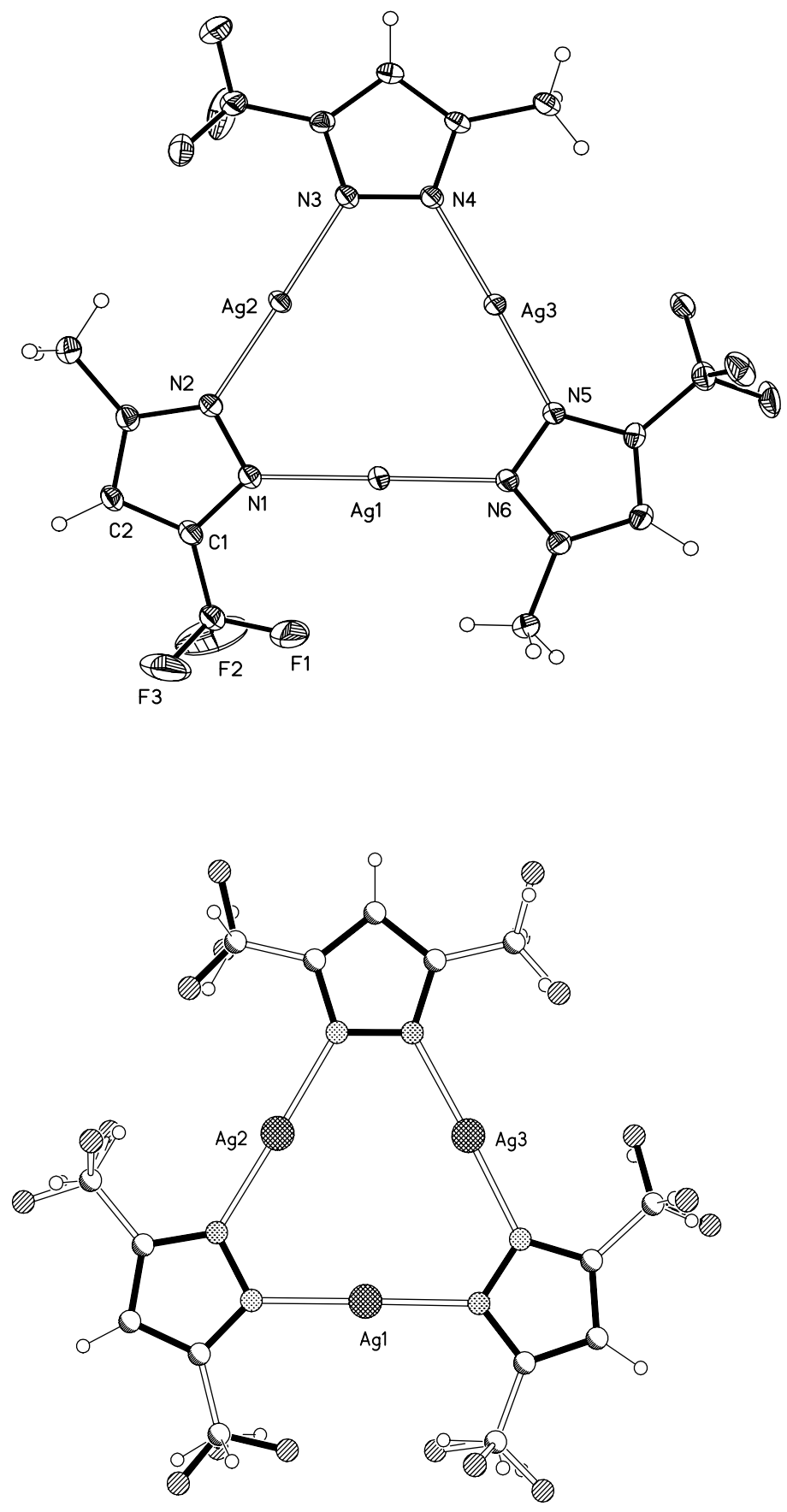

Figure S1. Molecular structure of $\left\{\left[3-\left(\mathrm{CF}_{3}\right), 5-\left(\mathrm{CH}_{3}\right) \mathrm{Pz}\right] \mathrm{Ag}\right\}_{3}$. ORTEP diagram (Top) and a view showing $\mathrm{CF}_{3} / \mathrm{CH}_{3}$ positional disorder (bottom) 


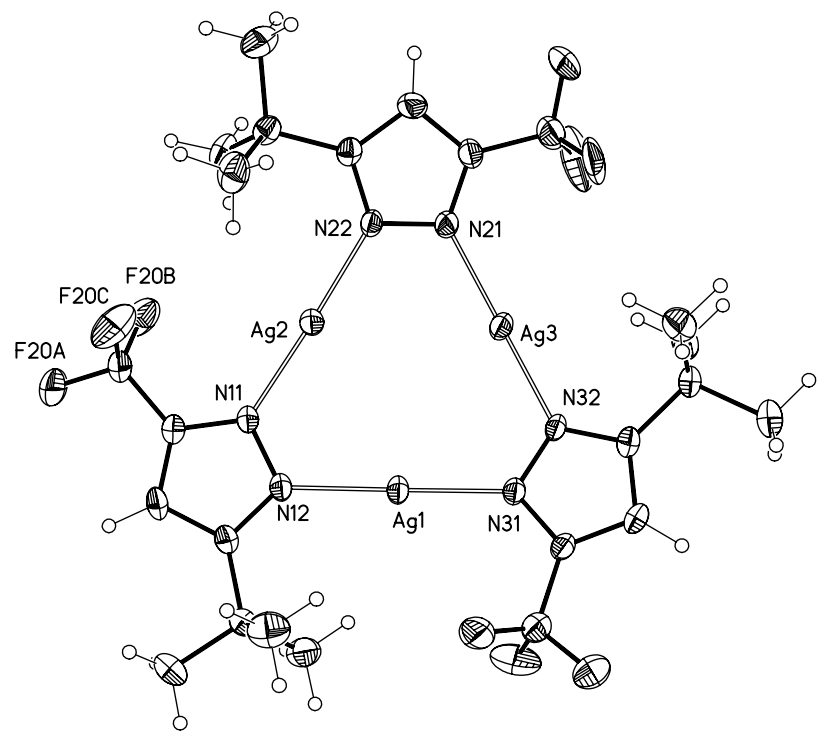

Figure S2. Molecular structure of $\left\{\left[3-\left(\mathrm{CF}_{3}\right), 5-\left(\mathrm{Bu}^{\mathrm{t}}\right) \mathrm{Pz}\right] \mathrm{Ag}\right\}_{3}$

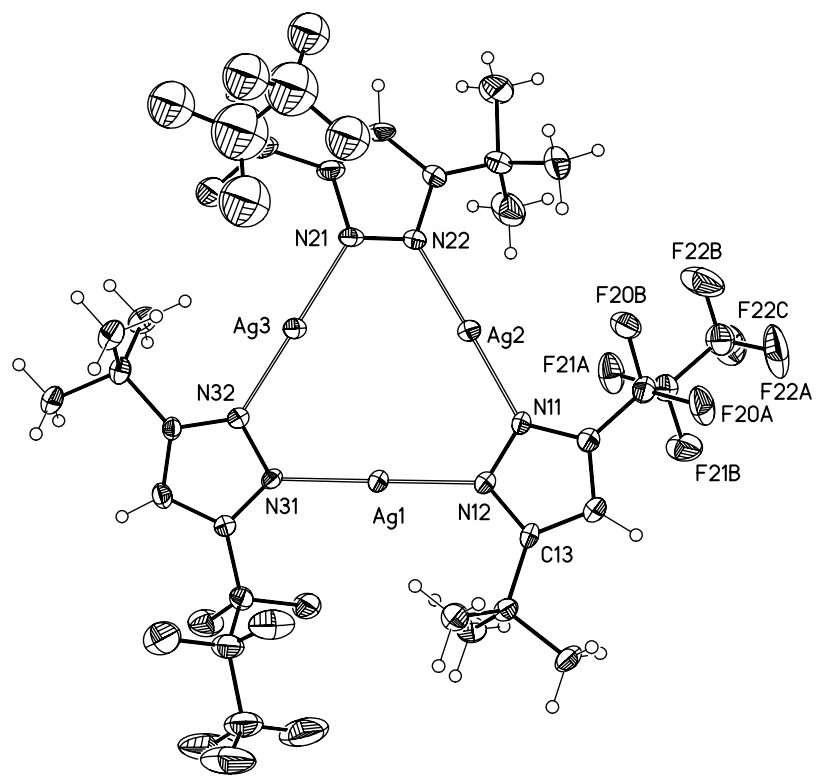

Figure S3. Molecular structure of $\left.\left\{\left[3-\left(\mathrm{C}_{3} \mathrm{~F}_{7}\right), 5-(\mathrm{Bu})^{t}\right) \mathrm{Pz}\right] \mathrm{Ag}\right\}_{3}$. 


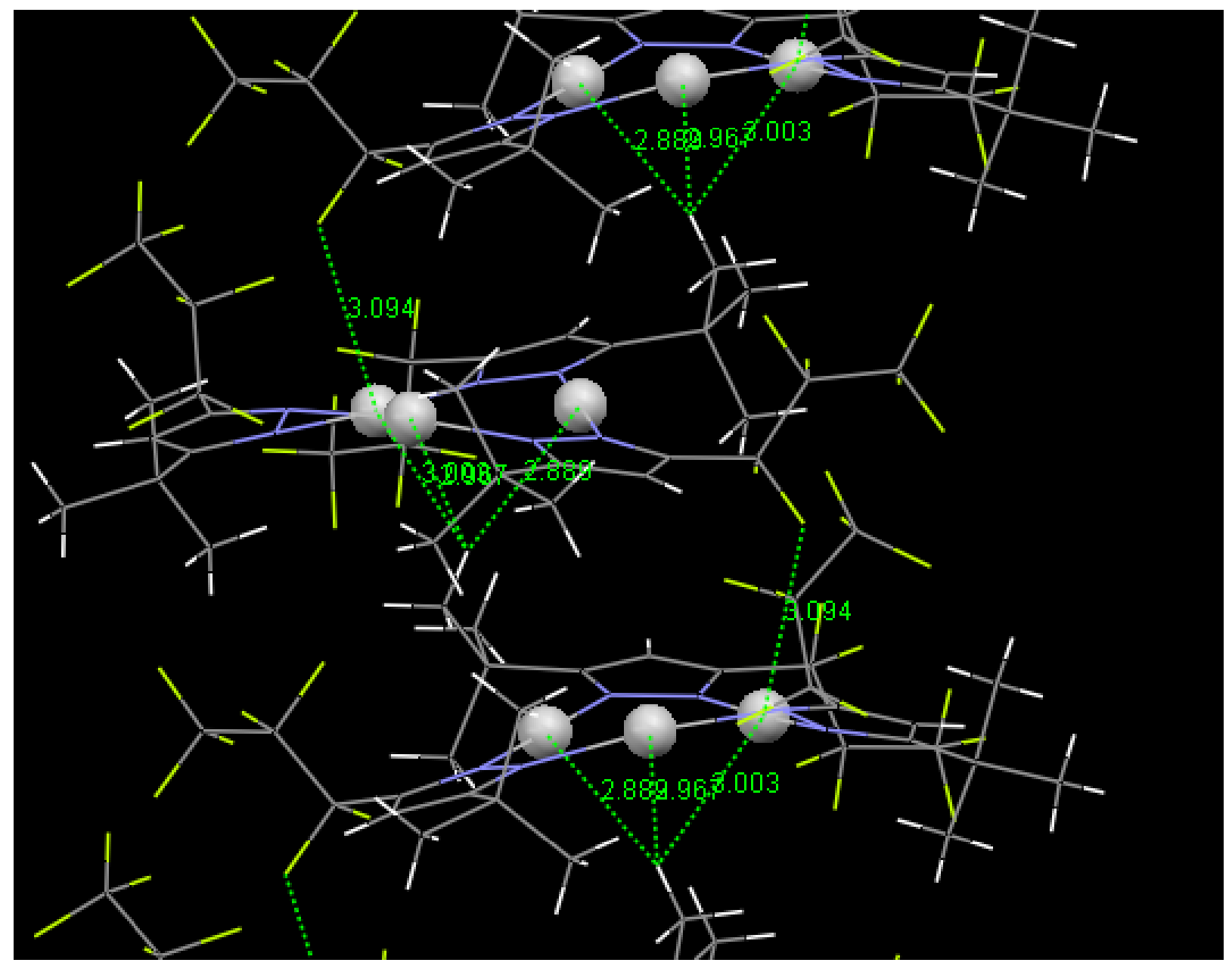

Figure S4. A view showing closest inter-trimer $A g{ }^{\cdots} \mathrm{F}$ and $\mathrm{Ag}{ }^{\cdots} \mathrm{H}$ distances of $\left\{\left[3-\left(\mathrm{C}_{3} \mathrm{~F}_{7}\right), 5-\right.\right.$ $\left.\left.\left(\mathrm{Bu}^{\mathrm{t}}\right) \mathrm{Pz}\right] \mathrm{Ag}\right\}_{3}$. 


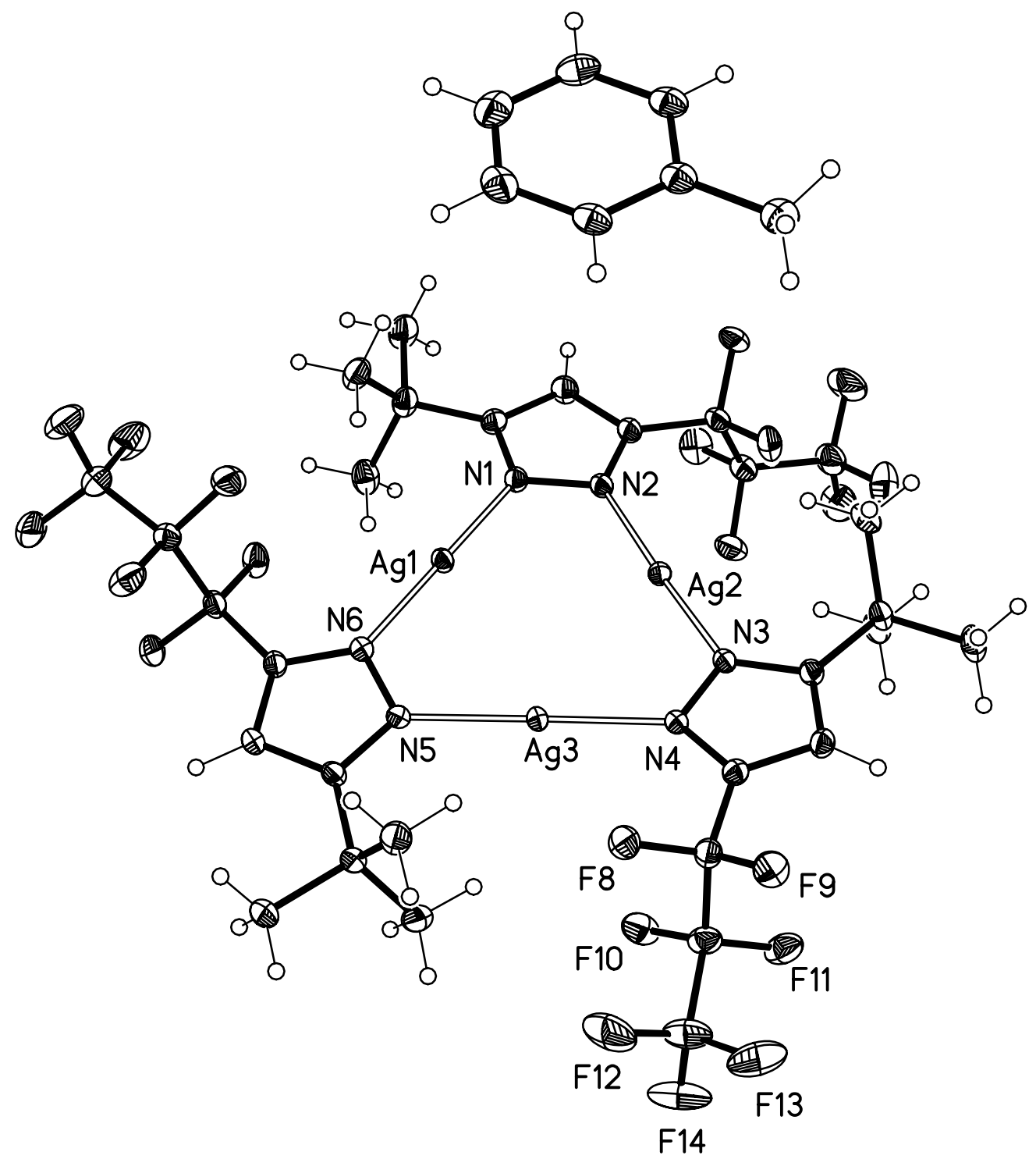

Figure S5. Molecular structure of $\left\{\left[3-\left(\mathrm{C}_{3} \mathrm{~F}_{7}\right), 5-\left(\mathrm{Bu}^{\mathrm{t}}\right) \mathrm{Pz}\right] \mathrm{Ag}\right\}_{3} \bullet$ (toluene) showing the repeating unit 


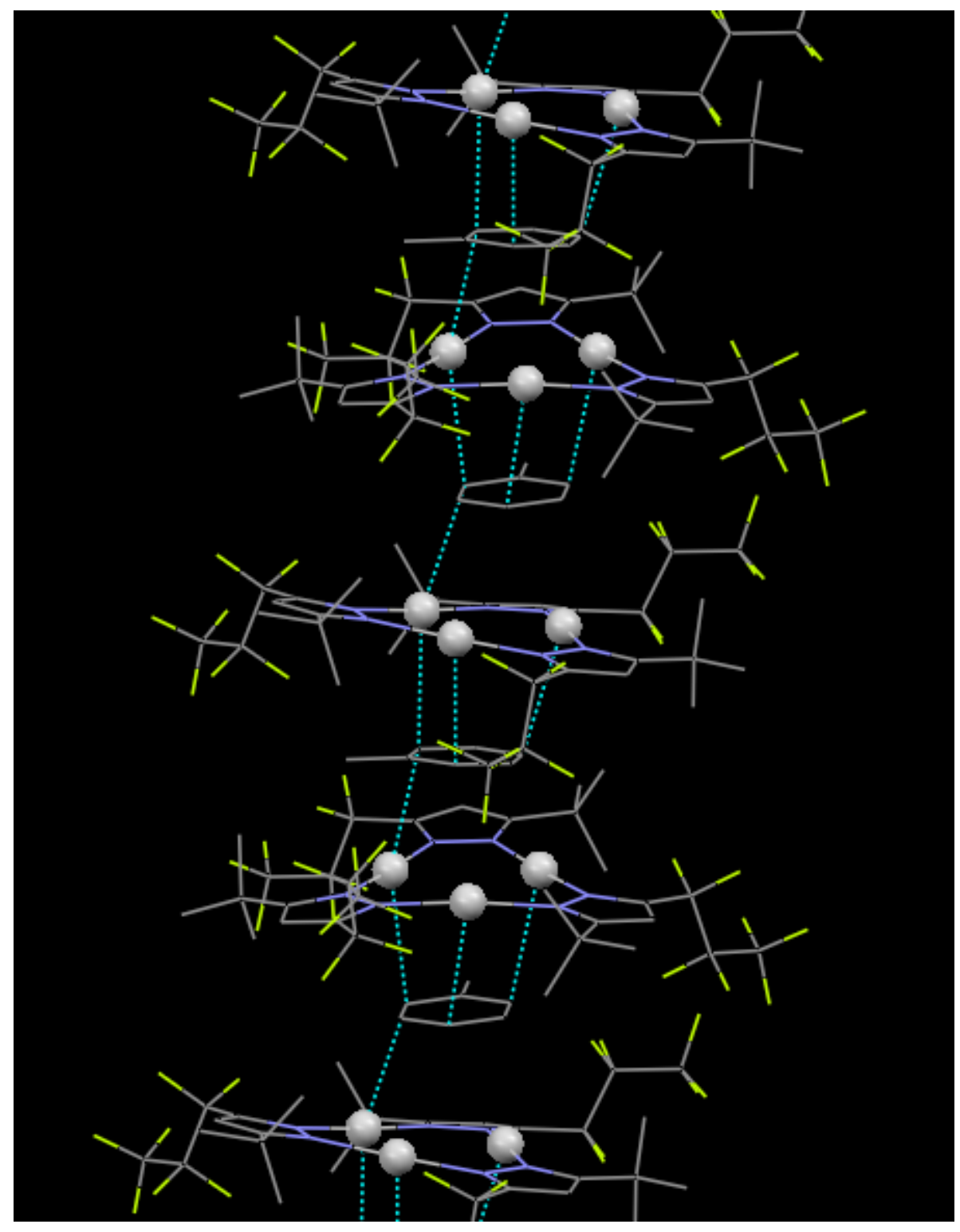

Figure S6. Molecular structure of $\left\{\left[\mathbf{A g}_{3}\right]^{\prime} \cdot[\text { toluene }]\right\}_{\infty}$ showing toluene-silver trimer contacts 

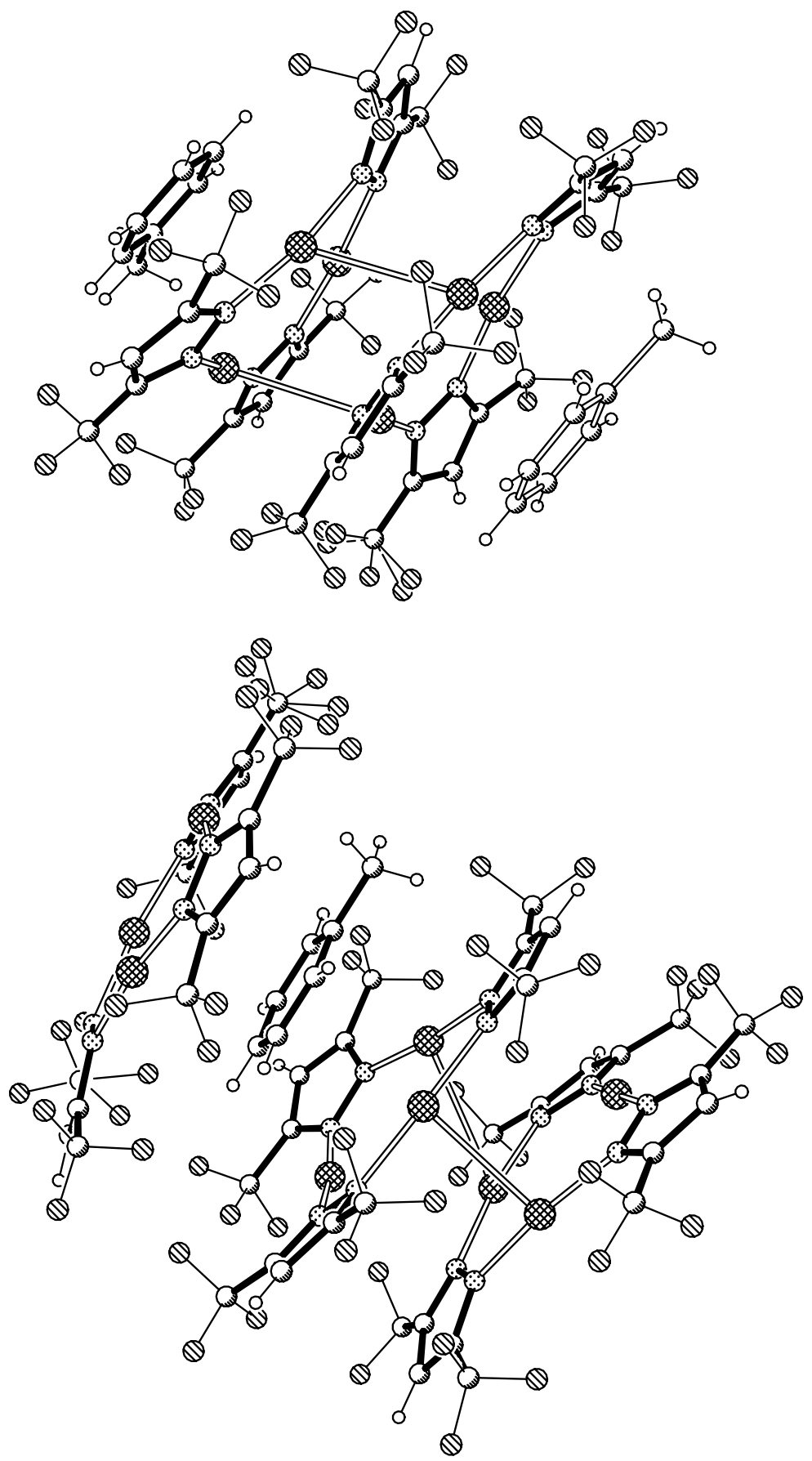

Figure S7. Asymmetric unit of $\left\{\left[\mathbf{A g}_{3}\right]_{2} \bullet[\text { toluene }]\right\}_{\infty}$. There are five $\left.\left[3,5-\left(\mathrm{CF}_{3}\right)_{2} \mathrm{Pz}\right] \mathrm{Ag}\right\}_{3}$ units and 2.5 toluene molecules in the asymmetric unit. 


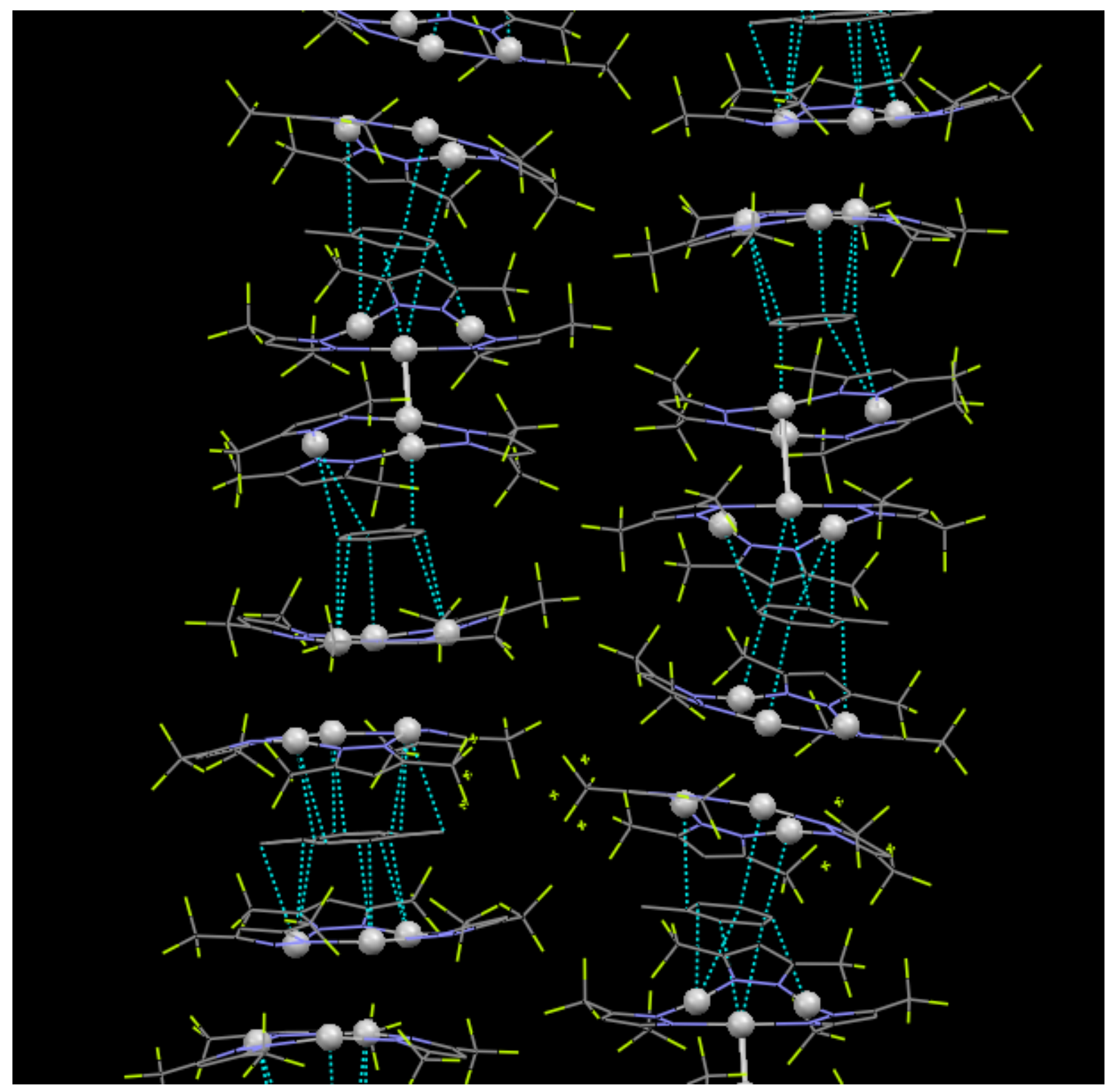

Figure S8. Molecular structure of $\left\{\left[\mathbf{A g}_{3}\right]_{2} \bullet[\text { toluene }]\right\}_{\infty}$ showing silver trimer and toluene contacts (note that one of the toluenes disordered) 

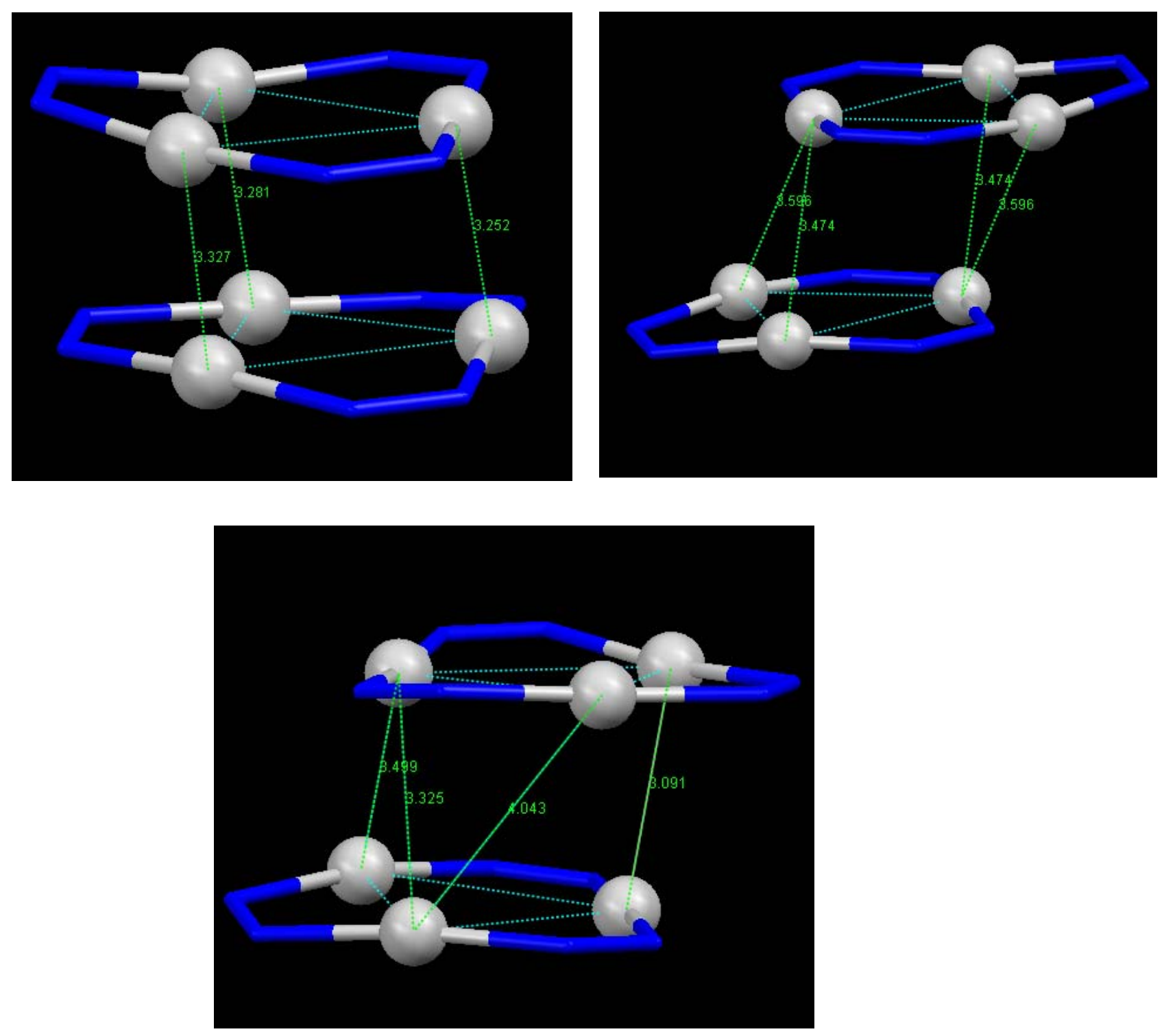

Figure S9. Figures showing various structures $\left(\mathrm{Ag}_{6}\right.$ core geometries $)$ of the dimer of $\{[3,5-$ $\left.\left.\left(\mathrm{CF}_{3}\right)_{2} \mathrm{Pz}\right] \mathrm{Ag}\right\}_{3}$ units in $\left\{\left[\mathbf{A g}_{3}\right]_{2} \bullet[\text { toluene }]\right\}_{\infty}$ 


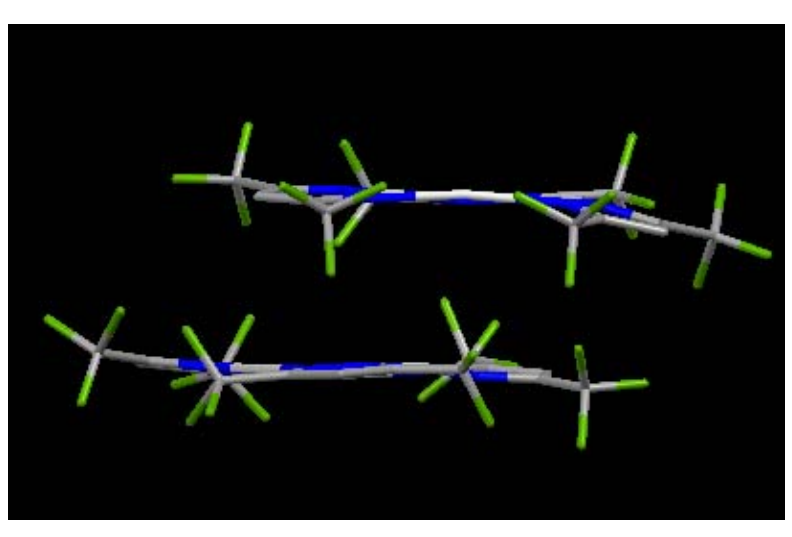

Parent $\left[\mathbf{A g}_{3}\right]$

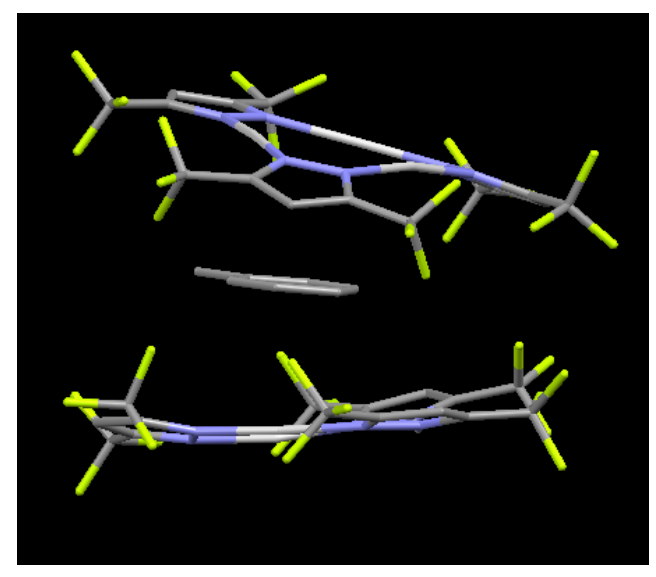

$\left\{\left[\mathbf{A g}_{3}\right]_{2} \cdot[\text { toluene }]\right\}_{\infty}$

Figure S10. A view showing the planarity of $\left[\mathbf{A g}_{3}\right]$ in the parent molecule, and the distortion to the $\left[\mathbf{A g}_{3}\right]$ unit during the $\left\{\left[\mathbf{A g}_{3}\right]_{2} \bullet[\text { toluene }]\right\}_{\infty}$ adduct formation, see also Figure S8.

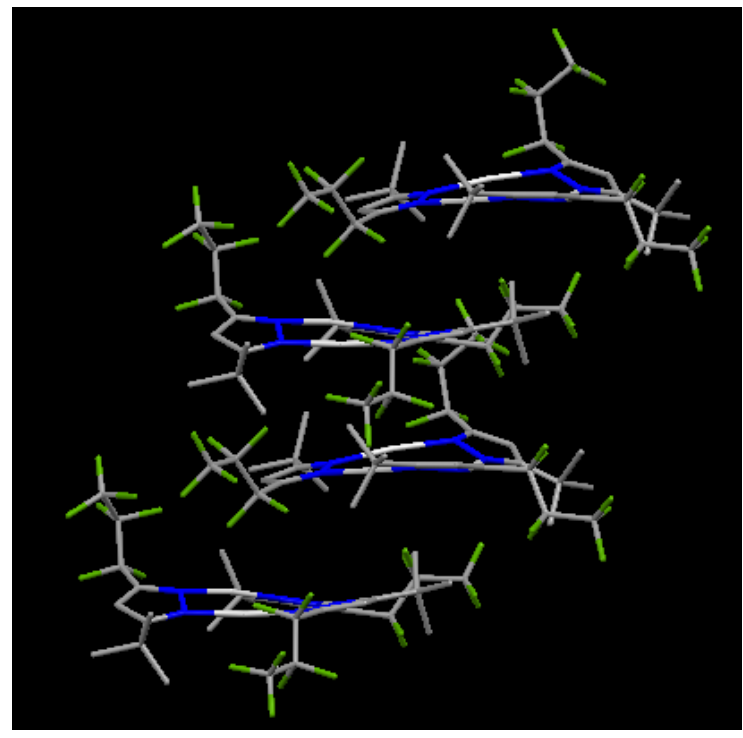

Parent $\left[\mathbf{A g}_{3}\right]^{\prime}$

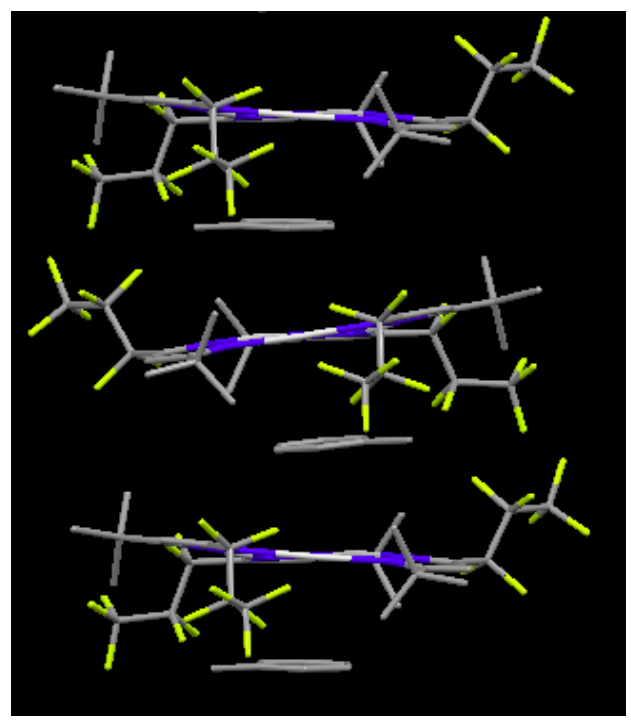

$\left\{\left[\mathbf{A g}_{3}\right] \cdot \cdot[\text { toluene }]\right\}_{\infty}$

Figure S11. A view showing structural changes to the $\left[\mathbf{A g}_{3}\right]^{\prime}$ ring during the $\left\{\left[\mathbf{A g}_{3}\right]^{\prime} \cdot[\text { toluene }]\right\}_{\infty}$ adduct formation. These figures also show the relative orientation of bulky t-Bu and $\mathrm{C}_{3} \mathrm{~F}_{7}$ substituents, and the effects of inter-trimer substituents interactions. 